\title{
New Technique of Clipless Laparoscopic Cholecystectomy
}

\author{
Ahmed A. ElGeidie \\ Faculty of Medicine, Mansoura University, Dakahlia, Egypt \\ Email: ahmedraoaf@mans.edu.eg
}

Received June 24, 2011; revised August 10, 2011; accepted September 14, 2011

\begin{abstract}
Background: In laparoscopic cholecystectomy (LC), application of clips is the standard method for controlling the cystic duct and artery. However, this is not without problems. We propose a modified technique for management of cystic duct and artery in LC. Methods: Since 2007, 328 patients presented with symptomatic gallstones were included. In those patients, the cystic artery was divided by monopolar cautery and the cystic duct was ligated intracorporeally using nonabsorbable suture. Results: Three patients $(0.9 \%)$ have bleeding from cauterized cystic artery; bleeding was controlled by diathermy in two of them and application of metal clip was necessary in the remaining patient. Cystic duct leak was detected in only one patient $(0.3 \%)$, and it was managed by percutaneous drainage. At follow up we did not encounter abnormalities suggestive of bile duct stricture. Conclusion: The proposed modification of LC is feasible, practical, safe and economic as well. It is associated with reduced risk of postoperative morbidity.
\end{abstract}

Keywords: Laparoscopic Cholecystectomy; Clipping; Ligation; Cystic Artery; Cystic Duct; Monopolar Diathermy

\section{Introduction}

There is no doubt that laparoscopic cholecystectomy (LC) has become the gold standard for the management of symptomatic gallstones disease [1,2]. Simple metal clips have been used by most surgeons to close the cystic duct and artery [3-12]. However, application of clips is associated with some problems. These include dislodgement of the clip or bile duct necrosis resulting in postoperative cystic duct leak $[3,4,7,11,12]$. Another clip-related problem was reported at long term follow up, which is late postcholecystectomy clip migration. This was reported to result in the biliary stone formation [13], duodenal ulcer [14,15] and even clip embolism [16].

Alternative techniques have included the use of locking absorbable clips, $[17,18]$ and the Harmonic Scalpel $[19,20]$. These are, however, more expensive, not readily available and used infrequently [5]. We describe a novel technique for dealing with cystic duct and artery during LC.

\section{Operative Technique}

Four ports are used. Calot's triangle is exposed and the peritoneal covering is scored posteriorly and anteriorly to visualize the cystic duct and artery. After obtaining the critical view of safety (Figure 1), the cystic artery is dealt with before cystic duct to avoid avulsion injury of the artery.

An Endo-Dissector is applied to the dissected cystic artery on the wall of gallbladder (Figure 2) and the artery is cauterized at two levels using monopolar diathermy at low-power setting. Then the cystic artery is divided by L-shaped hook diathermy (Figure 3).

After dividing the cystic artery, the base of gallbladder is freed from liver attachment to obtain a sufficient length of cystic duct and a good window behind it. A 15$\mathrm{cm}$ long thread of 2/0 silk suture (measured between the tip of the middle finger and the wrist) is introduced into the abdomen using a needle holder through the $10-\mathrm{mm}$ epigastric port. The tip of the thread is carried down to the window behind the cystic duct (Figure 4). The thread is picked up from behind the cystic duct by an Endodissector (or another needle holder) in the left hand. The cystic duct is ligated intracorporeally in a surgeon's knot configuration as described by Nathanson and colleagues [9] (Figure 5). The ends of the thread are cut with an Endo-Scissors. The distal end of the cystic duct, near to the Hartman's pouch, is occluded by the ligature in a similar way with a remaining thread and the duct is cut in between the two ties (Figure 6). The second tie is important to prevent spillage of gallbladder contents, and at the same time to leave the left hand instrument free thus facilitating dissection of gallbladder from liver bed. The cystic duct is cut between the two ligatures (Figure 7) and cholecystectomy is completed in the usual manner.

The ethics board of our hospital approved the performance of the study and an informed consent was obtained from all included patients. 


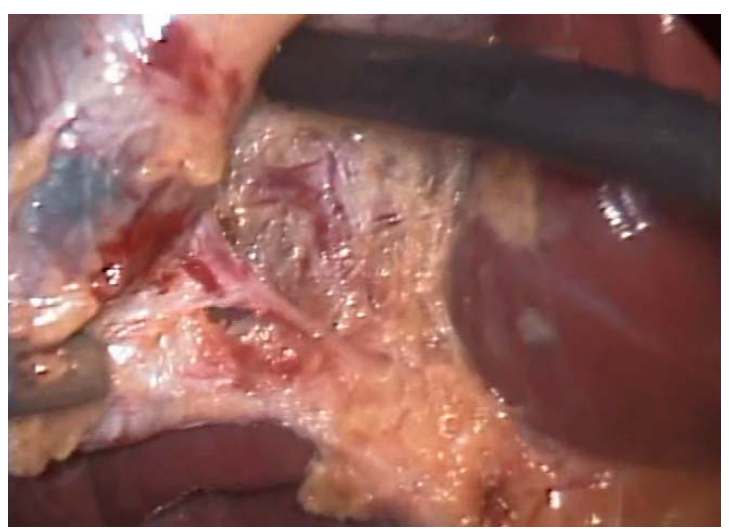

Figure 1. Critical view of safety with exposure of both cystic duct and artery.

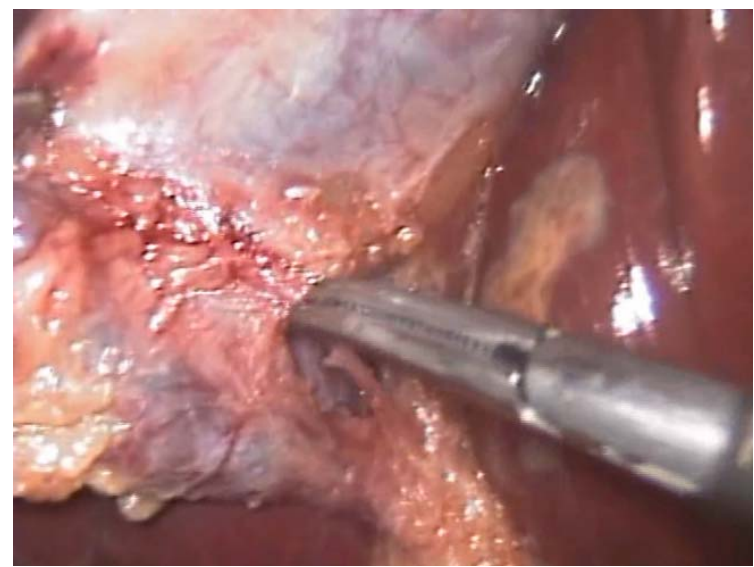

Figure 2. Application of Endo-Dissector to the dissected cystic artery close to gallbladder wall.

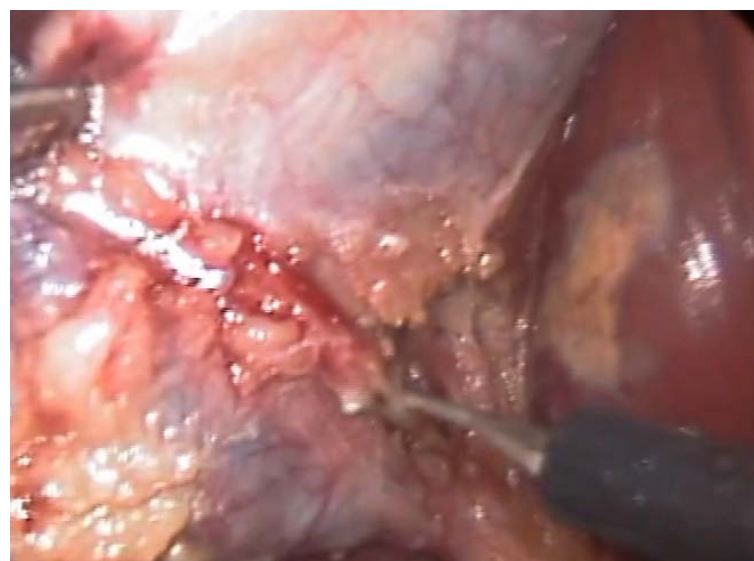

Figure 3. Division of cauterized cystic artery by L-shaped hook.

\section{Results}

Since Feb 2007, 328 cases of LC have been included in this study. There were no deaths or major bile duct injuries in either group. Intraoperative bleeding from cauterized cystic artery was detected in three patients $(0.9 \%)$.

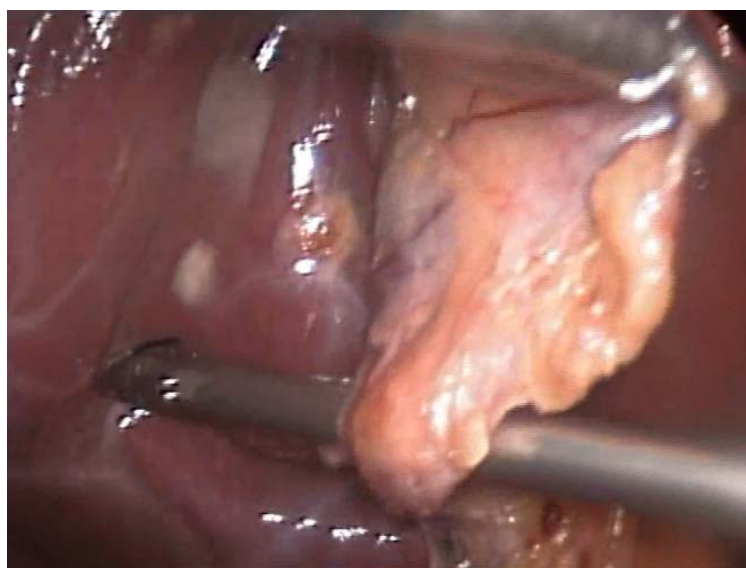

Figure 4. Passing the thread through the window behind the dissected cystic duct.

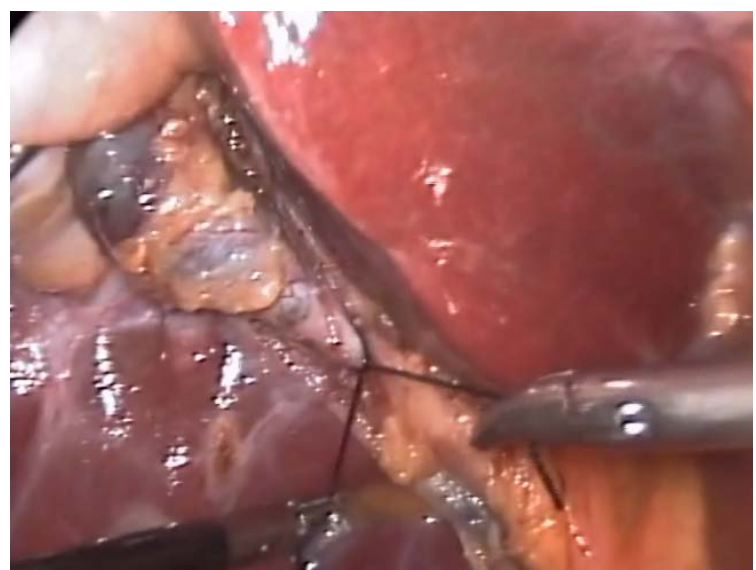

Figure 5. Intracorporeal tie of the cystic duct towards CBD side.

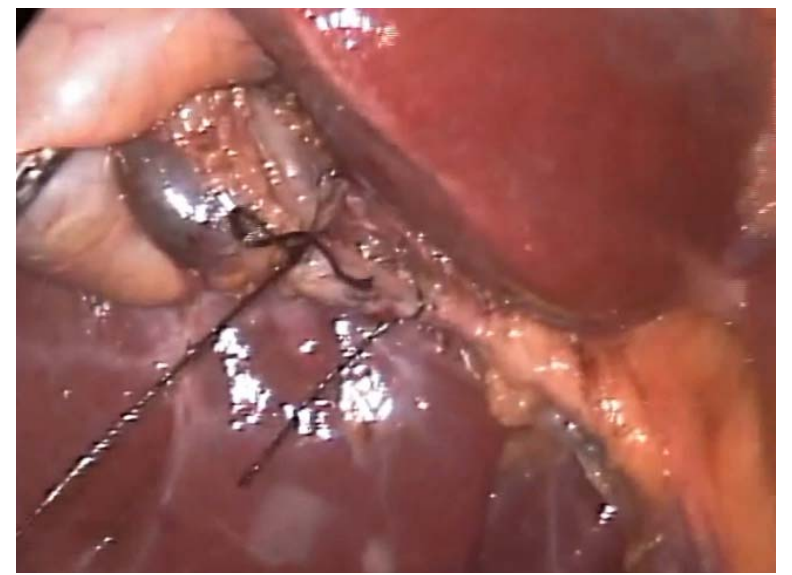

Figure 6. Second tie of the cystic duct toward the gallbladder side.

It was successfully controlled by diathermy in two of them. Application of clip was needed to control of bleeding in the remaining patient. No postoperative bleeding was reported. Cystic duct leak was diagnosed in only one 


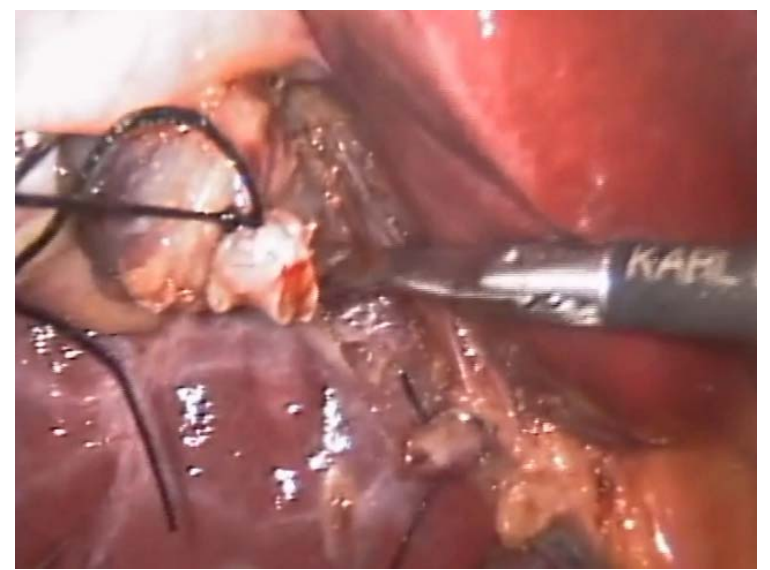

Figure 7. Cutting the cystic duct between the two ties.

patient $(0.3 \%)$. It was managed by percutaneous tube drainage and broad spectrum antibiotics without the need for further endoscopic or surgical management.

\section{Discussion}

Simple metal clips have been used by most surgeons to close the cystic duct since Muhe reported the first successful LC in 1985 [3,12] However, the use of simple metal clips has many disadvantages. Postoperative cystic duct leaks occur in up to $2 \%$ of cases $[3,4,7,11,12]$. Cystic duct leak is a potentially serious complication causing biloma formation or biliary peritonitis. Cystic duct leakage can occur for the following variety of reasons: inadequate closure of the duct due to mismatch of the clip arms, necrosis of the duct at the site of clipping, or slippage of the clips off the end of the duct [6]. Furthermore, in the process of application, the metallic clips can fall from the applicator [21-23]. There are other disadvantages to using metal clips. There is a significant inflammatory reaction to metallic clips [24], and there are artifacts in subsequent computed tomography (CT) or magnetic resonance imaging (MRI) scans [22,23,25]. Metallic clips also can migrate. Cetta et al. [26] reported that clip migration occurred in 18 of 71 patients over the course of 1 year. Clips migrated from their initial site to either the peritoneal cavity or the common bile duct, serving as a potential nidus for gallstone formation [27]. Locking absorbable clips were used instead of simple clips to close the cystic duct [5,17], but these clips are expensive. Recently, Harmonic Scalpel was proposed as an alternative technique for cystic duct closure $[19,20]$. However, it is also expensive and not readily available and therefore used infrequently [5,24,25].

We had found many advantages to the simple ligation of the cystic duct. It is feasible and practical since the only required advanced skill is the ability to make intracorporeal knotting. This is a simple maneuver that could be learnt easily. Moreover, we found that intracorporeal knotting technique should be mastered by surgeons willing to perform more advanced and complex laparoscopic procedures. Additionally, this technique avoids the intrinsic disadvantages of the use of clips. Beyond doubt simple ties are always available and very economic.

We did not record bile duct injuries due to spread of monopolar diathermy current while dividing the cystic artery. We think that absence of this complication in our study patients is due to cauterizing the artery on the wall of the gallbladder far away from hilar structures after adequate arterial dissection.

It is to be noted that some prerequisites should be fulfilled to obtain the best outcome when adopting this technique; 1) the cystic artery should be controlled prior to cystic duct ligation to avoid the possibility of torn artery during maneuvers needed for duct ligation; 2) the cystic artery should be dissected up to the gallbladder wall sufficiently away from the hilar structures to minimize the risk of diathermy current spread; and 3) the distal end of cystic duct should be ligated also to avoid spillage of gallbladder contents that may add to infective complications, and also to allow the use of the left hand instrument for dissection of gallbladder from liver.

We can conclude that the proposed modification of LC is feasible, practical, safe and more economic as well.

\section{REFERENCES}

[1] E. C. Ellison and L. C. Carey, "Cholecystectomy, Cholecystostomy, and Intraoperative Evaluation of the Biliary Tree,” In: J. R. Baker and J. E. Fishcer, Eds., Mastery of Surgery, 4th Edition, Lippincott Williams \& Wilkins, Philadelphia, 2001.

[2] J. S. Barkun, A. N. Barkun, J. S. Sampalis, et al., "Randomised Controlled Trial of Laparoscopic versus Mini Cholecystectomy. The McGill Gallstone Treatment Group,” Lancet, Vol. 340, No. 8828, 1992, pp. 1116-1119. doi:10.1016/0140-6736(92)93148-G

[3] S. Adamsen, O. H. Hansen, P. F. Jensen, et al., "Bile Duct Injury during Laparoscopic Cholecystectomy: A Prospective Nationwide Series,” Journal of the American College of Surgeons, Vol. 184, 1997, pp. 571-578.

[4] X. Huang, Y. Feng and Z. Huang, "Complications of Laparoscopic Cholecystectomy in China: An Analysis of 39,238 Cases," Chinese Medical Journal, Vol. 110, 1997, pp. 704-706.

[5] K. L. Leung, K. H. Kwong, W. Y. Lau, et al., “Absorbable Clips for Cystic Duct Ligation in Laparoscopic Cholecystectomy," Surgical Endoscopy, Vol. 10, 1996, pp. 49-51. doi:10.1007/s004649910012

[6] A. J. McMahon, G. Fullarton, J. N. Baxter and P. J. O_Dwyer, "Bile Duct Injury and Bile Leakage in Laparoscopic Cholecystectomy,” British Journal of Surgery, Vol. 82, No. 3, 1995, pp. 307-313. doi:10.1002/bjs.1800820308

[7] M. Miroshnik, A. Saafan, S. Koh, et al., "Biliary Tract 
Injury in Laparoscopic Cholecystectomy: Results of a Single Unit,” ANZ Journal of Surgery, Vol. 72, No. 12, 2002, pp. 867-870. doi:10.1046/j.1445-2197.2002.02587.x

[8] E. Muhe, "Die erste Cholecystektomie durch das Laparoskop: English Summary,” Langenbecks Archiv fur Klinische Chirurgie, Vol. 369, 1986, pp. 804.

[9] L. K. Nathanson, D. W. Easter and A. Cuschieri, "Ligation of the Structures of the Cystic Pedicle during Laparoscopic Cholecystectomy," American Journal of Surgery, Vol. 161, No. 3, 1991, pp. 350-354. doi:10.1016/0002-9610(91)90596-6

[10] W. Reynolds Jr., "The First Laparoscopic Cholecystectomy," Journal of the Society of Laparoendoscopic Surgeons, Vol. 5, No. 4, 2001, pp. 89-94.

[11] J. A. Shea, M. J. Healey, J. A. Berlin, et al., "Mortality and Complications Associated with Laparoscopic Cholecystectomy,” Annals of Surgery, Vol. 224, No. 5, 1996, pp. 609-620. doi:10.1097/00000658-199611000-00005

[12] U. S. Wise, G. L. Glick and M. Landeros, "Cystic Duct Leak after Laparoscopic Cholecystectomy: A Multiinstitutional Study,” Surgical Endoscopy, Vol. 10, No. 12, 1996, pp. 1189-1193. doi:10.1007/s004649900276

[13] V. H. Chong, “Iatrogenic Biliary Stone,” Surgical Technology International, Vol. 14, 2005, pp. 147-155.

[14] L. D. Reis, "Surgical Clips Incorporated into a Duodenal Ulcer: A Rare Complication after Elective Laparoscopic Cholecystectomy,” Endoscopy, Vol. 32, 2000, p. S3.

[15] C. C. Yao, H. H. Wong, C. C. Chen, et al., "Migration of Endoclip into Duodenum. A Rare Complication after Laparoscopic Cholecystectomy," Surgical Endoscopy, Vol. 15, 2001, p. 217.

[16] K. Ammann, J. Kiesenebner, M. Gadenstätter, et al., "Embolism of a Metallic Clip: An Unusual Complication Following Laparoscopic Cholecystectomy,” Digestive Surgery, Vol. 17, No. 5, 2000, pp. 542-544. doi:10.1159/000051959

[17] A. L. Rohatgi and A. Widdison, "An Audit of Cystic Duct Closure in Laparoscopic Cholecystectomies," Surgical Endoscopy, Vol. 20, No. 6, 2006, pp. 875-877. doi:10.1007/s00464-004-2253-9

[18] H. Yano, K. Okada, M. Kinuta, et al., "Efficacy of Ab- sorbable Clips Compared with Metal Clips for Cystic Duct Ligation in Laparoscopic Cholecystectomy," Surgery Today, Vol. 33, No. 1, 2003, pp. 18-23. doi:10.1007/s005950300003

[19] J. Westervalt, "Clipless Cholecystectomy: Broadening the Role of the Harmonicsc Alpel," Journal of the Society of Laparoendoscopic Surgeons, Vol. 8, No. 3, 2004, pp. 283-285.

[20] G. D. Tebala, “Three-Port Laparoscopic Cholecystectomy by Harmonic Dissection without Cystic Duct and Artery Clipping,” American Journal of Surgery, Vol. 191, No. 5, 2006, pp. 718-720. doi:10.1016/j.amjsurg.2005.07.029

[21] D. L. Clarke-Pearson and W. T. Creasman, “A Clinical Evaluation of Absorbable Polydiaxanone Ligating Clips in Abdominal and Pelvic Operations," Surgery Gynecology \& Obstetrics, Vol. 161, 1985, pp. 250-252.

[22] B. Geissler, F. Lindemann, L. Hausser and J. Witte, "Dislocation of Clips of the Cystic Duct Stump," Zentralblatt fur Chirurgie, Vol. 123, 1998, pp. 102-105.

[23] C. J. Schaefer, P. M. Colombani and G. W. Geelhoed, “Absorbable Ligating Clips,” Surgery Gynecology \& Obstetrics, Vol. 154, 1982, pp. 513-516.

[24] F. Michel, Y. Ponsot, J. Roland, et al., "Biological Tolerance to Polydiaxanone Absorbable Clips: A Comparison with Metallic Ligating Clips,” European Surgical Research, Vol. 17, No. 6, 1985, pp. 383-387. doi:10.1159/000128495

[25] D. Weishaupt, H. H. Quick, D. Nanz, et al., "Ligating Clips for Three-Dimension MR Angiography at $1.5 \mathrm{t}$ in Vitro Evaluation,” Radiology, Vol. 214, 2000, pp. $902-$ 907.

[26] F. Cetta, C. Baldi, F. Lombardo, et al., "Migration of Metallic Clips Used during Laparoscopic Cholecystectomy and Formation of Gallstones around Them: Surgical Implications from a Prospective Study," Journal of Laparoendoscopic \& Advanced Surgical Techniques, Vol. 7, No. 1, 1997, pp. 37-46. doi:10.1089/lap.1997.7.37

[27] V. H. Chong and C. F. Chong, "Biliary Complications Secondary to Post-Cholecystectomy Clip Migration: A Review of 69 Cases,” Journal of Gastrointestinal Surgery, Vol. 14, No. 4, 2010, pp. 688-696. doi:10.1007/s11605-009-1131-0 